\title{
Mathematical Modeling of Ignition of Droplets of Coal-Water Slurry Containing Petrochemicals Using Ansys Fluent
}

\author{
Dmitrii V. Antonov, Ksenia Yu. Vershinina, Genii V. Kuznetsov, Pavel A. Strizhak \\ National Research Tomsk Polytechnic University \\ Lenina Avenue, 30, Tomsk, Russia, 634050 \\ pavelspa@tpu.ru
}

\begin{abstract}
We developed the mathematical model, which provides a fairly accurate reproduction of the experimental values of the integral characteristics (minimum ignition temperatures, ignition delay times, coordinates of the combustion front birth) of ignition of droplets of coal-water slurries containing petrochemicals (CWSP) in the flow of hot oxidizer. Numerical investigations were carried out for ignition process of droplets of slurries based on typical wastes of coal processing (filter-cakes). Ignition delay times of CWSP droplets were determined under varying droplet sizes (radiuses) from $0.25 \mathrm{~mm}$ to $1.5 \mathrm{~mm}$, velocities and temperatures of stream of high temperature gas (oxidizer) from $0.5 \mathrm{~m} / \mathrm{s}$ to $3 \mathrm{~m} / \mathrm{s}$ and from $700 \mathrm{~K}$ to $1000 \mathrm{~K}$ correspondingly. These ranges of parameters variation correspond to main conditions of combustion chambers. We got a satisfactory agreement of the results of mathematical modeling and the known experimental data. The possibility of using Ansys Fluent software package for numerical simulation of CWSP droplet ignition is proved. Good (deviation does not exceed 5-10\%) correlation between modeling results and experimental data on the characteristics of the ignition process inertia was established.
\end{abstract}

Keywords: coal-water slurry containing petrochemicals, droplet, ignition, ignition delay time, mathematical modeling

\section{Introduction}

Today in the world more than $40 \%$ [1-3] of thermal power plants and small energy facilities use solid fossil fuels (coal of different grades) to produce electricity and heat. The operation of a coal thermal power industry associated with large-scale pollution of the environment, including emissions of greenhouse gases, ash, smog formation (almost $80 \%$ of emissions of $\mathrm{CO}_{2}$ and sulfur and nitrogen oxides occur at energy facilities). However, despite of serious environmental consequences from the combustion of solid fuels, at present and in the coming decades coal will be most demanded and affordable fuel for most regions of the world.

During the last 25-30 years the technologies of coal-water slurries are rather actively developed worldwide $[4,5]$. The main objectives that can be achieved by using coal-water slurries (CWS) and coal-water slurries containing petrochemicals (CWSP) [6,7] are, primarily, reduction of emissions of sulfur and nitrogen oxides, fly ash as compared to pulverized coal, as well as involvement of low-grade coals (even fire dangerous lignite) and a variety of petroleum products (waste motor and industrial oils, sludge, etc.) as a raw material. It is important to note, that technology of CWSP allows using components of varying quality (for example, substandard coal dust) and combustible wastes of coal and oil processing for combustion in slurries. Development of science-based technology of CWSP will significantly expand the raw material base of thermal power industry. As a consequence, there will be a real alternative to high quality fuels (coal, oil and gas).

The purpose of the present work is the development of mathematical model in Ansys Fluent software package for prognostic investigation of ignition integral characteristics of single droplets of coal-water slurry containing petrochemicals in high temperature oxidizer flow.

\section{Physical and Mathematical Model}

In accordance with experimental results [7] we developed the model, which describes the process of ignition of single CWSP droplet in oxidizer flow (fig. 1). In the mathematical simulation we considered experimentally determined [7] successive stages of ignition of CWSP droplet, in particular: heating of the surface layer; evaporation of moisture and devolatilization; gas phase ignition of mixture of volatiles and flammable liquid vapors; heating of carbon residue and 
distribution of the front of the heterogeneous combustion across the surface of the fuel particle; intensive burning carbon; completion of carbon burning with the movement of the combustion front from the front part of the droplet to the back part (with respect to the oxidizer flow); inert heating of ash residue in oxidizer flow.

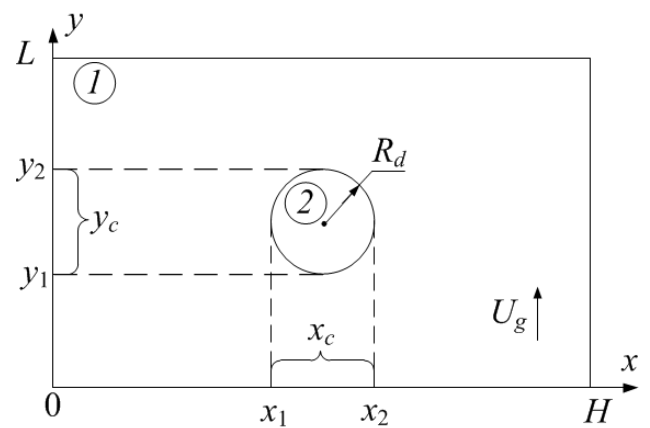

Fig. 1: Scheme of the task solution domain for modeling ignition of CWSP droplet: 1 -oxidizer flow, 2 - droplet.

Typical wastes of coal processing (filter cakes) were considered as components of CWSP. We examined filter-cakes of coking, nonbanking and low-caking coals. This waste is generated at coal washing plants. As part of the technological process, coal is washed with a surfactant solution and then screened into separate fractions. Water used for washing the rock is fed into special tanks, where coal particles are deposited. Coal-water slurry is pumped out and sent to belt press filters to force out water. A wet residue (water and coal mixture) is known as a filter cake. The average size of the coal dust particles in filter cake is less than 100 microns.

Table 1 shows the results of technical and elemental analysis of filter cakes. The water fraction in initial filter cakes (after receiving from coal-washing factories) and combustion heat are presented in Table 2.

Table 1: Results of technical sample (analytical) analysis of filter cakes.

\begin{tabular}{|c|c|c|c|c|c|c|c|c|c|}
\hline Sample of filter cake & $\begin{array}{c}W^{a}, \\
\%\end{array}$ & $A^{d}, \%$ & $\begin{array}{c}V^{\text {daf }} \\
\%\end{array}$ & $\begin{array}{c}Q^{a}, \mathrm{~V}, 10^{6} \\
\mathrm{~J} / \mathrm{kg}\end{array}$ & $\begin{array}{c}C^{\text {daf }}, \\
\%\end{array}$ & $\begin{array}{c}H^{\text {daf }}, \\
\%\end{array}$ & $\begin{array}{c}N^{\text {daf }}, \\
\%\end{array}$ & $\begin{array}{c}S^{\text {daf }}, \\
\%\end{array}$ & $\begin{array}{c}O^{\text {daf }} \\
\%\end{array}$ \\
\hline $\begin{array}{c}\text { Dry filter cake of coking coal (the enrichment } \\
\text { factory "Severnaya") }\end{array}$ & 0 & 26.46 & 23.08 & 24.83 & 79.79 & 4.486 & 1.84 & 0.868 & 12.70 \\
\hline $\begin{array}{c}\text { Dry filter cake of low-caking coal (the enrichment } \\
\text { factory "Chernigovskaya Koksovaya") }\end{array}$ & 0 & 50.89 & 30.16 & 15.23 & 77.30 & 4.783 & 1.93 & 0.326 & 15.32 \\
\hline $\begin{array}{c}\text { Dry filter cake of nonbaking coal (the enrichment } \\
\text { factory "Kaltanskaya Energeticheskaya") }\end{array}$ & 0 & 21.20 & 16.09 & 26.92 & 87.97 & 4.104 & 2.23 & 0.526 & 5.03 \\
\hline
\end{tabular}

Note. $A^{d}$ - ash level of dry filter cake, $\% ; W^{a}$ - humidity of analytical sample of filter cake in an air-dry state, $\%$; $V^{d a f}-$ yield of volatiles of filter cake to a dry ash-free state; $Q_{s, V}^{a}$ - enthalpy of combustion of analytical sample of filter cake, J/kg; $C^{d a f}, H^{d a f}, N^{d a f}, O^{d a f}, S_{t}^{d a f}-$ fraction of carbon, hydrogen, nitrogen, oxygen and sulfur in the sample of filter cake converted to a dry ash-free state, $\%$.

Table 3: Properties of filter cakes in initial (wet) state.

\begin{tabular}{|c|c|c|}
\hline Sample & Mass fraction of dry matter, $\%$ & $Q^{a}{ }_{s, V}, 10^{6} \mathrm{~J} / \mathrm{kg}$ \\
\hline Filter cake of coking coal & 56.5 & 14.1 \\
\hline Filter cake of low-caking coal & 62.1 & 9.5 \\
\hline Filter cake of nonbaking coal & 60.9 & 16.4 \\
\hline
\end{tabular}

Fig. 1 shows the scheme of the solution domain of the problem of heat and mass transfer in conditions of CWSP droplet ignition. Characteristic sizes of the solution domain $(x=H, y=L)$ were taken much larger than the sizes of the CWSP droplet $\left(D=x_{c}=x_{2}-x_{1}, D=y_{c}=y_{2}-y_{1}\right)$.

Interrelated processes of heat and mass transfer, chemical and physical transformations for the considered system (fig. 1) can be described by the following non-stationary differential equations in partial derivatives. When using coal 
processing waste (filter cakes) as main fuel component, convective flows inside droplet are insignificant (it was shown in experimental study [7] at ignition of CWSP droplets). Therefore this effect was not taken into account in the model of CWSP ignition.

For the gas mixture (mixture of vapors of water and combustible liquid component of CWSP, volatiles, air) $(0<x<H$, $0<y<L)$ :

continuity equation:

$$
\frac{\partial^{2} \psi}{\partial x^{2}}+\frac{\partial^{2} \psi}{\partial y^{2}}=-\omega, \text { where } \omega=\frac{\partial v}{\partial x}-\frac{\partial u}{\partial y}
$$

equation of motion:

$$
\frac{\partial \omega}{\partial t}+u \frac{\partial \omega}{\partial x}+v \frac{\partial \omega}{\partial y}=\gamma\left(\frac{\partial^{2} \omega}{\partial x^{2}}+\frac{\partial^{2} \omega}{\partial y^{2}}\right)+\beta g_{\mathrm{y}} \frac{\partial T_{1}}{\partial x}, \text { where } u=\frac{\partial \psi}{\partial y}, v=\frac{\partial \psi}{\partial x}
$$

energy equation:

$$
\left(\frac{\partial T_{1}}{\partial t}+u \frac{\partial T_{1}}{\partial x}+v \frac{\partial T_{1}}{\partial y}\right)=a_{1}\left(\frac{\partial^{2} T_{1}}{\partial x^{2}}+\frac{\partial^{2} T_{1}}{\partial y^{2}}\right)+\sum_{i=1}^{3} Q_{i} W_{i}, W_{i}=A_{\mathrm{ri}} T_{1}^{\beta_{\mathrm{ri}}} e^{-E_{\mathrm{ri}} / R_{t} T_{1}}
$$

diffusivity equation:

$$
\rho_{1}\left(\frac{\partial C_{f}}{\partial t}+u \frac{\partial C_{f}}{\partial x}+v \frac{\partial C_{f}}{\partial y}\right)=\rho_{1} D_{1}\left(\frac{\partial^{2} C_{f}}{\partial x^{2}}+\frac{\partial^{2} C_{f}}{\partial y^{2}}\right)-\sum_{i=1}^{3} W_{i}
$$

balance equation:

$$
C_{f}+C_{\mathrm{O} 2}=1, C_{f}=C_{\mathrm{CH} 4}+C_{\mathrm{N} 2}+C_{\mathrm{H} 2 \mathrm{O}}+C_{\mathrm{CO} 2}+C_{\mathrm{CO}}+C_{\mathrm{H} 2} .
$$

For CWSP particle $\left(0<r<R_{d}, 0<\varphi<\pi\right)$ :

energy equation in spherical coordinates:

$$
C_{2} \rho_{2} \frac{\partial T_{2}}{\partial t}=\lambda_{2}\left[\frac{1}{r^{2}} \frac{\partial}{\partial r}\left(r^{2} \frac{\partial T_{2}}{\partial r}\right)+\frac{1}{r^{2} \sin (\varphi)} \frac{\partial}{\partial \varphi}\left(\sin (\varphi) \frac{\partial T_{2}}{\partial \varphi}\right)\right]+\sum_{i=4}^{6} Q_{i} W_{i}-W_{d} Q_{d}
$$

thermal decomposition reaction equation:

$$
W_{d}=\rho_{2}(1-\xi) k_{d} \exp \left[-E_{d} / R_{t} T_{2}\right] ;
$$

kinetics equation of thermal decomposition reaction:

$$
\frac{\partial \xi}{\partial t}=(1-\xi) k_{d} \exp \left[-E_{d} / R_{t} T_{2}\right] .
$$

Volumetric fractions of gas mixture components were calculated from their mass concentrations by the expressions: 


$$
\begin{gathered}
\eta_{11}=\frac{C_{\mathrm{f}} / \rho_{11}(T)}{C_{\mathrm{f}} / \rho_{11}(T)+C_{\mathrm{O} 2} / \rho_{12}(T)}, \\
\eta_{12}=\frac{C_{\mathrm{O} 2} / \rho_{12}(T)}{C_{\mathrm{f}} / \rho_{11}(T)+C_{\mathrm{O} 2} / \rho_{12}(T)}, \\
\eta_{11}+\eta_{12}=1 .
\end{gathered}
$$

Thermal characteristics of the gas mixture as heterogeneous system, were calculated as follows:

$$
\begin{aligned}
& \lambda_{1}(T)=\lambda_{11}(T) \cdot \eta_{11}+\lambda_{12}(T) \cdot \eta_{12}, \\
& C_{1}(T)=C_{11}(T) \cdot \eta_{11}+C_{12}(T) \cdot \eta_{12}, \\
& \rho_{1}(T)=\rho_{11}(T) \cdot \eta_{11}+\rho_{12}(T) \cdot \eta_{12} .
\end{aligned}
$$

Initial conditions ( $t=0): T=T_{g 0}, C_{\mathrm{O} 2}=1, C_{f}=0, \psi=0, \omega=0$ at $0<x<H, 0<y<L ; T=T_{\mathrm{C} 0}$ at $0<r<R_{d}, 0<\varphi<\pi$.

The boundary conditions at $t>0$ :

$$
\begin{gathered}
T=T_{\mathrm{g}}, C_{\mathrm{O} 2}=1, C_{\mathrm{f}}=0, \frac{\partial \psi}{\partial x}=U_{g} \text { at } x=0,0<y<L ; \\
\frac{\partial^{2} T}{\partial x^{2}}=0, \frac{\partial^{2} C_{\mathrm{O} 2}}{\partial x^{2}}=0, \frac{\partial^{2} C_{\mathrm{f}}}{\partial x^{2}}=0, \frac{\partial \psi}{\partial x}=0 \text { at } x=H, 0<y<L ; \\
\frac{\partial T}{\partial t}=0, C_{\mathrm{O} 2}=0, C_{\mathrm{f}}=0, \frac{\partial \psi}{\partial y}=0 \text { at } y=0,0<x<H ; \\
\frac{\partial T}{\partial t}=0, C_{\mathrm{O} 2}=0, C_{\mathrm{f}}=0, \frac{\partial \psi}{\partial y}=0 \text { at } y=L, 0<x<H .
\end{gathered}
$$

The thermal effect of evaporation on the border "CWSP particle - gas" is taken into account in the boundary conditions of the fourth kind:

$$
\begin{gathered}
R=R_{2}, 0<\varphi<\pi, \lambda_{2} \frac{\partial T_{2}}{\partial r}=\lambda_{1} \frac{\partial T_{1}}{\partial r}-W_{\mathrm{ew}} Q_{\mathrm{ew}}-W_{\mathrm{eC}} Q_{\mathrm{eC}}+W_{\mathrm{iw}} Q_{\mathrm{w}}+\sum_{i=1}^{6} Q_{\mathrm{i}} W_{\mathrm{i}}, T_{1}=T_{2}, u=W_{\mathrm{ew}} / \rho_{2}, \\
\text { where } W_{\mathrm{ew}}=\rho_{5} D_{5} \frac{\partial C_{\mathrm{H} 2 \mathrm{O}}}{\partial r}, W_{\mathrm{eC}}=\rho_{6} D_{6} \frac{\partial C_{6}}{\partial r} .
\end{gathered}
$$

Index $i$ corresponds to the number of chemical reaction in Table 3. The value of the rate of evaporation of liquid components was set in accordance with the experimental data [7]. Table 3 shows the basic chemical reaction.

Indexes in the in the above equations correspond to the following meanings: 1 - gas-vapor mixture; 2 - CWSP particle; 3 - water in liquid state; 4 - organic liquid; 5 - water vapor; 6 - vapors of organic liquid; 11 - products of chemical reactions; 12 - oxidizer.

Table 3: Description of chemical reactions.

\begin{tabular}{|c|l|c|c|c|c|}
\hline № & \multicolumn{1}{|c|}{ Reaction } & $Q, 10^{6} \mathrm{~J} / \mathrm{kg}$ & $A_{\mathrm{r}}, \mathrm{s}^{-1}$ & $\beta_{\mathrm{r}}$ & $E_{\mathrm{r}}, \mathrm{J} / \mathrm{mol}$ \\
\hline 1 & $\mathrm{CH}_{4}+1.706 \cdot \mathrm{O}_{2}=\mathrm{CO}_{2}+1.543 \cdot \mathrm{H}_{2} \mathrm{O}$ & 55.55 & $5.6 \cdot 10^{10}$ & 0 & 103800 \\
\hline 2 & $\mathrm{H}_{2}+0.5 \cdot \mathrm{O}_{2}=\mathrm{H}_{2} \mathrm{O}$ & 141.9 & $2.137 \cdot 10^{14}$ & 0 & 129800 \\
\hline 3 & $\mathrm{CO}+0.5 \cdot \mathrm{O}_{2}=\mathrm{CO}_{2}$ & 10.09 & $1.4 \cdot 10^{12}$ & 0 & 96800 \\
\hline
\end{tabular}




\begin{tabular}{|c|l|c|c|c|c|}
\hline 4 & $\mathrm{C}(s)+0.5 \cdot \mathrm{O}_{2}=\mathrm{CO}$ & 44 & 92000 & 0 & 69180 \\
\hline 5 & $\mathrm{C}(s)+\mathrm{CO}_{2}=2 \cdot \mathrm{CO}$ & 52 & 5000 & 0 & 6000 \\
\hline 6 & $\mathrm{C}(s)+\mathrm{H}_{2} \mathrm{O}=\mathrm{H}_{2}+\mathrm{CO}$ & 118.49 & $5.6 \cdot 10^{12}$ & 0 & 36207 \\
\hline
\end{tabular}

The system of equations (1)-(8) with appropriate initial and boundary conditions was solved with the use of Ansys Fluent software package by finite element method [8]. The method consists in the search for solutions of differential equations in the field, divided into finite number of elements. Ansys Fluent was used to build the mesh containing triangles elements over the domain. The mesh was performed with meshes containing 63804 cells for individual droplets. Type of approximating function is chosen arbitrarily in each of the elements. Approximating function is zero outside of its element. The values of the functions at the nodes are the solution of the problem.

The area with dimensions $L=10 \cdot 10^{-3} \mathrm{~m}, H=30 \cdot 10^{-3} \mathrm{~m}$ was chosen for the analysis of the interaction of moving particles with the gas-vapor mixture. In the numerical solution of formulated task of heat and mass transfer time steps were $\Delta t=0.1 \mathrm{~s}$ and spatial coordinate steps were $\Delta x=\Delta y=0.01 \mathrm{~mm}$. Near the phase transition boundaries the coordinate grid was condensed (to $\Delta x=\Delta y=\Delta r=0.001 \mathrm{~mm}$ ). The algorithm for solving the problem in terms of physical and chemical transformations corresponded the model [7]. The computation is carried out on a 4-processor computer with $3.4 \mathrm{GHz}$ Intel Core i5-3570 CPU, 32 GB memory, 64K L1 cache, and 1MB L2 cache. The computation time ranges from 10 to $300 \mathrm{~min}$.

\section{Results and Discussion}

Fig. 2 shows the temperature fields in the system (Fig. 1) that correspond to ignition of single CWSP droplet [7]. As a result of numerical simulation we have established (Fig. 2) that heterogeneous ignition of CWSP droplet occurs in the area of its surface from the incoming flow. We can make a reasonable conclusion about the origin of the combustion in this area. Then, the combustion distribution occurs in the direction of oxidizer flow.

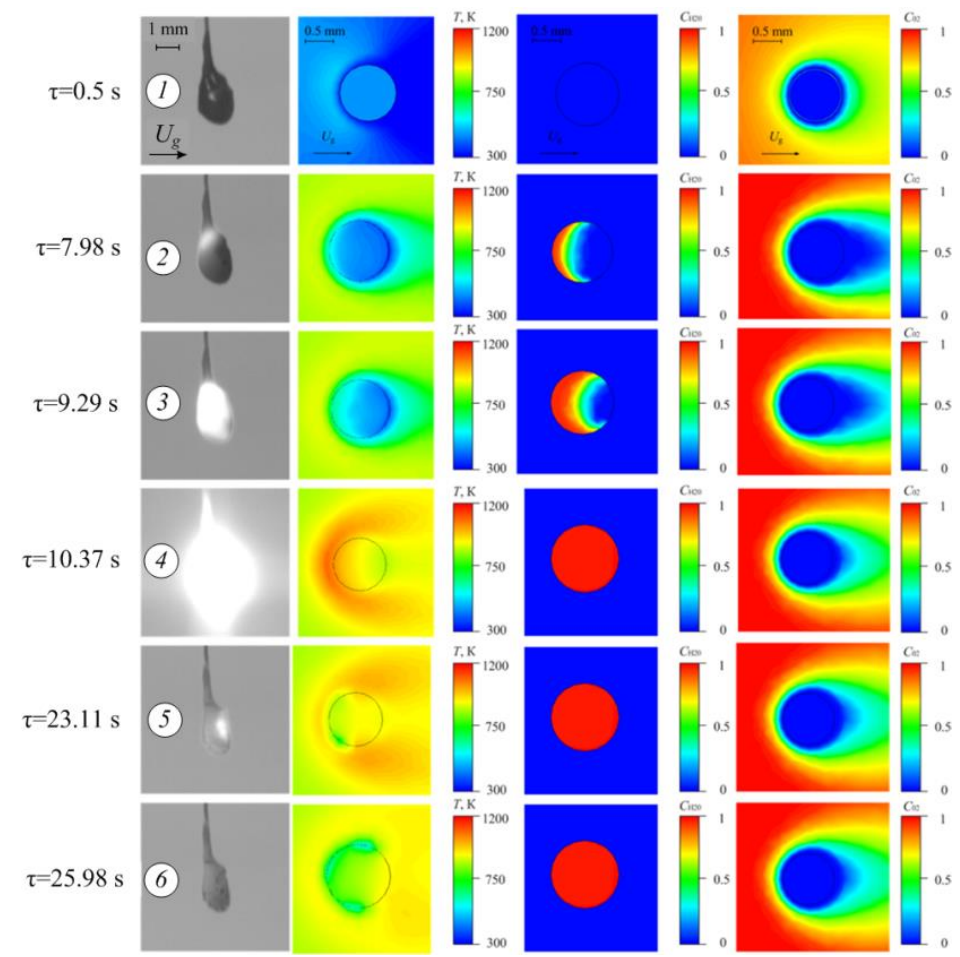

Fig. 2: The calculated temperature and concentration fields and frames of videograms [7] during heating, ignition and combustion of the CWSP in oxidizer flow (comparison of experimental [7] and theoretical studies): 1 - leakage of the heated oxidant flow to the droplet; 2 - heating the surface layer of droplet, the evaporation of moisture and devolatilisation; 3 - gas phase ignition of mixture of volatiles and flammable liquid vapors, heating the carbon residue; 4 - heterogeneous ignition of carbon residue and distribution the front of the heterogeneous combustion over the entire surface of dehydrated fuel droplet; 5 - intensive carbon burnout; 6 - completion of the carbon burnout. 
We can see from Fig. 2 the increase (up to $1200 \mathrm{~K}$ ) of temperature of gas-vapor mixture at gas phase ignition of volatile and subsequent initiation of heterogeneous combustion of CWSP dehydrated particle. Trends of temperature in the center of the fuel droplet $\left(T_{\mathrm{d}}\right)$ were calculated to separate stages of investigated processes of ignition of CWSP. Fig. 3 shows the typical changes of $T_{\mathrm{d}}$ in time. Relevant extremes of temperature are clearly visible. Temperatures in centre $\left(T_{\mathrm{d}}\right)$ and on the surface $\left(T_{\mathrm{s}}\right)$ of particle, which are typical for each step of CWSP ignition, are shown in one coordinate system. The maximum heat release is typical (Fig. 3) for heterogeneous carbon combustion stage, as in the experiments [7].

Registered in the experiments [7] and the obtained theoretical temperature gradients indicate that attempts to describe the complex of heat and mass transfer, chemical and physical transformations in the CWSP droplet within the models, which do not take into account the spatial inhomogeneity of the temperature fields, can lead to large deviations between real (experimentally registered) values and ignition characteristics obtained from mathematical simulations. Numerical studies have shown that the main problem is experimental dependences of the evaporation of water and the CWSP liquid fuel component, as well as experimental dependences of the rates of chemical reactions taking place in the depth and on the surface of the droplet, in the gas boundary layer, on the temperature. Accordingly, the temperature change at some point at a certain distance from the droplet surface of 50-70 $\mathrm{K}$ can lead to changes in the rate of physicochemical transformations 1.5-2 times. The main characteristics of the ignition process (limit (minimum) ignition temperature and ignition delay times) are changed accordingly.

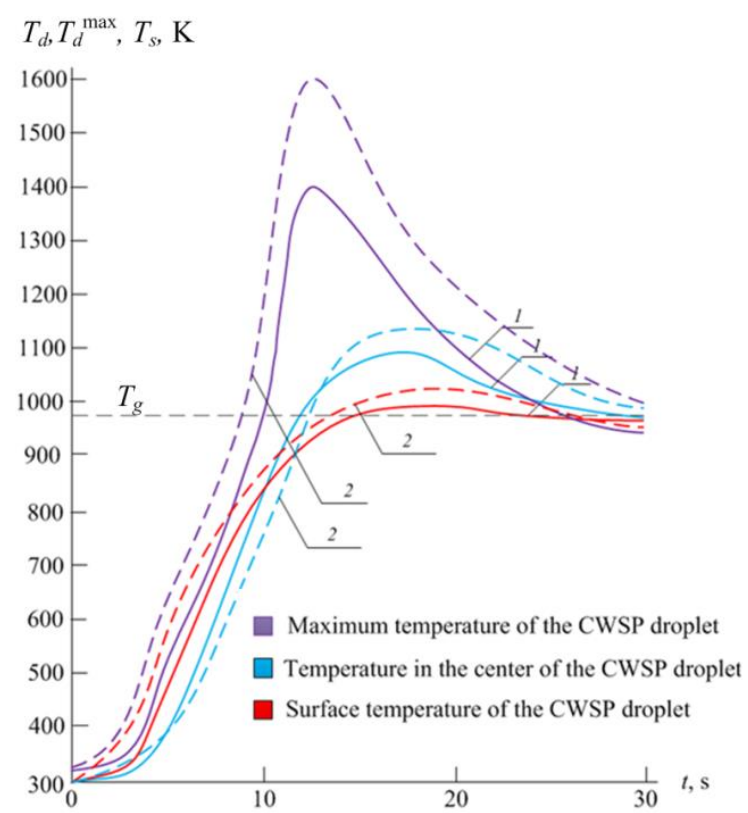

Fig. 3: Temperature trends of CWSP (90\% filter cake of coking coal, $10 \%$ heavy oil) in center $\left(T_{\mathrm{d}}\right)$ and on surface $\left(T_{\mathrm{s}}\right)$ of droplet, as well as maximum temperature $\left(T_{\mathrm{d}}{ }^{\max }\right.$ ) (at $R_{\mathrm{d}} \approx 1 \mathrm{~mm}, T_{\mathrm{g}} \approx 973 \mathrm{~K}, V_{\mathrm{g}} \approx 3 \mathrm{~m} / \mathrm{s}$ ): 1 - experimental data [7], 2 - results of mathematical modeling.

Fig. 4 shows the dependencies of ignition delay times on oxidizer temperature for different component compositions of CWSP. These dependencies have nonlinear appearance. This is because the rates of gas phase oxidation of products of coal thermal decomposition and evaporation of liquid combustible component, rates of heterogeneous ignition of carbon residue and thermal decomposition of the organic part of coal vary exponentially with increasing temperature. 


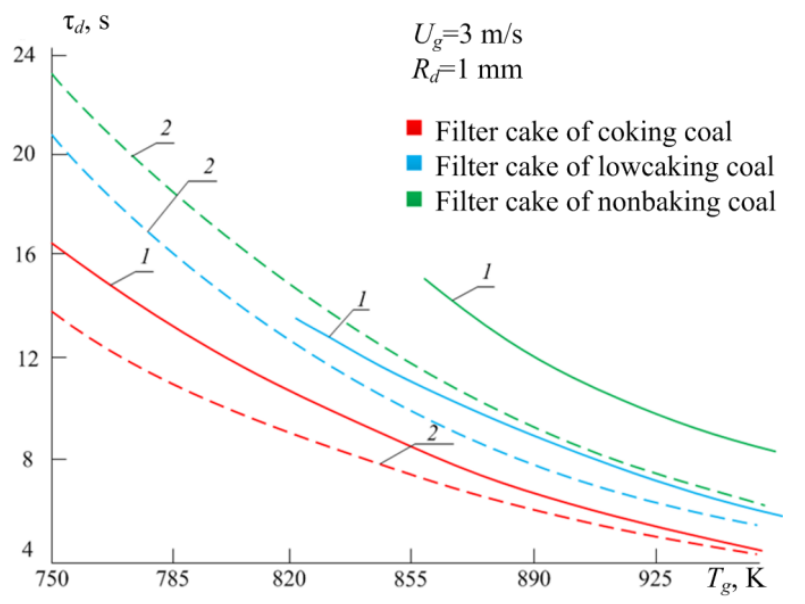

Fig. 4: Dependences of ignition delay on oxidizer temperature for different CWSP compositions (90\% filter cake, $10 \%$ heavy oil): $1-$ experimental data [7], 2 - results of mathematical modeling.

The obtained dependences $\tau_{\mathrm{d}}\left(R_{\mathrm{d}}\right)$ (Fig. 5) are caused by the nonlinear increase in the ignition delay time with increasing droplet size. This is due to the fact that with $R_{\mathrm{d}}$ increase an area of water evaporation becomes larger. Since the dependencies of the rates of gas-phase combustion of thermal decomposition products and evaporation of water and liquid combustible component on gas concentration are power law, the dependences $\tau_{\mathrm{d}}\left(R_{\mathrm{d}}\right)$ also correspond to power functions in some areas. In general terms, they are non-linear (Fig. 5).

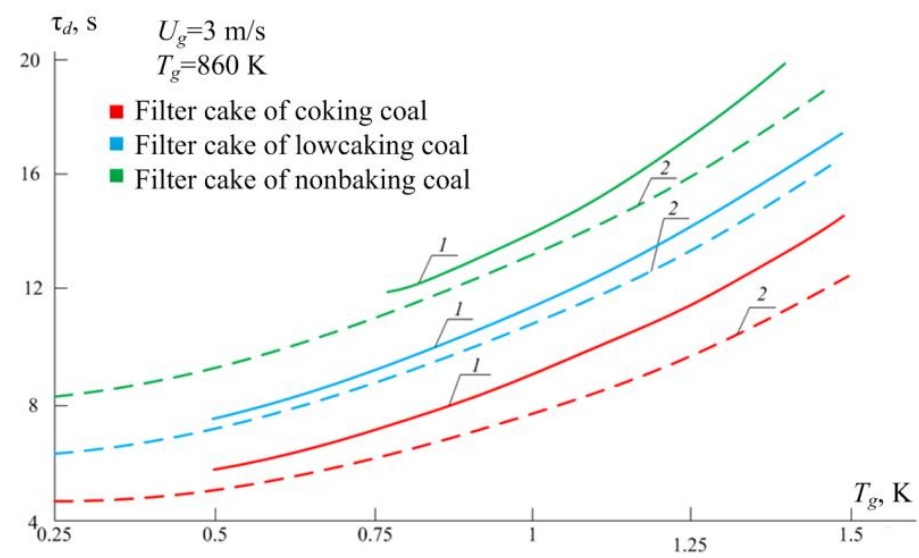

Fig. 5: Dependencies of ignition delay on sizes (radiuses) of droplets for different CWSP compositions (90\% filter cake, $10 \%$ heavy oil): 1 - experimental data [7], 2 - results of mathematical modeling.

Dependencies of ignition delay of CWSP droplet on the velocity of oxidizer flow are also nonlinear (Fig. 6). This is mainly due to the relevant influence of $U_{\mathrm{g}}$ on conditions of heat transfer on the border "drop of fuel - oxidant". The modeling results have shown that the influence of $U_{\mathrm{g}}$ on the time $\tau_{\mathrm{d}}$ increases with decreasing oxidizer temperature. 


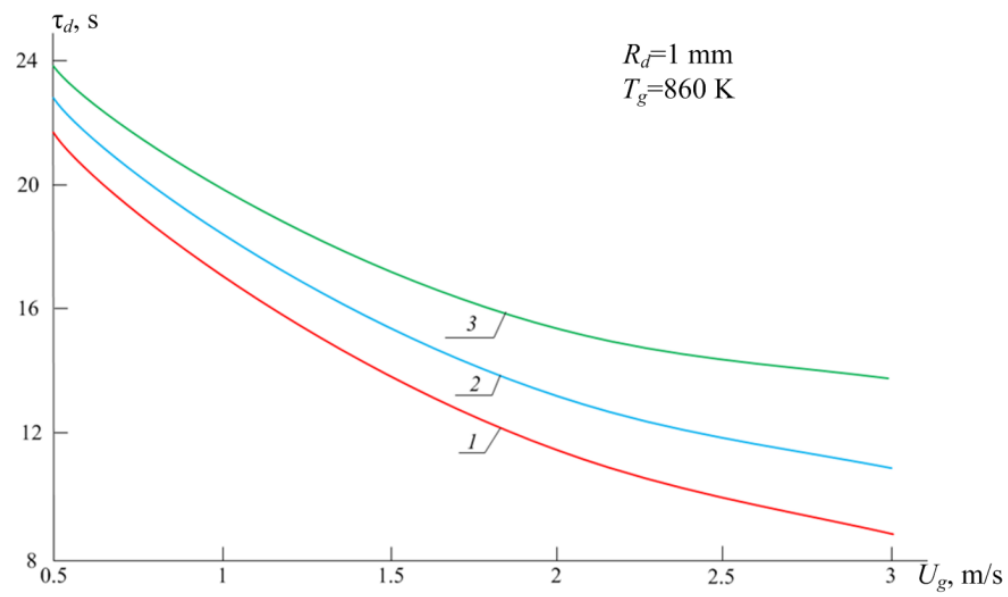

Fig. 6: Dependencies of ignition delay on gas velocity for different CWSP compositions (90\% filter cake, $10 \%$ heavy oil) under mathematical modeling: 1 - filter cake of coking coal; 2 - filter cake of nonbaking coal; 3 - filter cake of low caking coal.

\section{Conclusion}

Ansys Fluent software package can be used for reliably determining the basic characteristics of the CWSP ignition in furnaces and steam boilers using velocities [9] of evaporation of water and liquid fuel components of fuel slurry under high temperatures of outer gaseous medium. In the first approximation, we can use the experimental method [9]. The main objective in this case is not whether to choose the constants (thermokinetic or thermal), under which the mathematical modeling software Ansys Fluent (or any other) gives good agreement with experiment. The goal is to divide the process of ignition into a group of processes (described by equations (1)-(8) with the appropriate boundary conditions) for which the thermokinetic or thermal parameters can be determined experimentally with high adequacy. Therefore, when using commercial software packages the main goal is to detail the physical and chemical processes and use parameter values, which were determined experimentally. An urgent task is to obtain reliable information base with the experimental values of these constants. In particular, it is suitable for the typical and widespread CWSP compositions to determine evaporation rates under high temperatures corresponding to furnace processes in power plants. Similar problems to be solved for the chemical reaction constants (thermal decomposition, gas-phase and heterogeneous oxidation) of respective CWSP components.

\section{Nomenclature}

$a$ - thermal diffusivity, $\mathrm{m}^{2} / \mathrm{s} ; A_{\mathrm{r}}$ - pre-exponential factor of a chemical reaction, $\mathrm{s}^{-1} ; C$ - specific heat, $\mathrm{J} /(\mathrm{kg} \cdot \mathrm{K}) ; C_{\mathrm{CH} 4}$ - mass concentration of methane in the gas-vapor mixture; $C_{\mathrm{CO}}-$ mass concentration of carbon monoxide in the gas-vapor mixture; $C_{\mathrm{CO} 2}$ - mass concentration of carbon dioxide in the gas-vapor mixture; $C_{\mathrm{f}}-$ mass concentration of combustible matter in the gas-vapor mixture; $C_{\mathrm{H} 2}-$ mass concentration of hydrogen in the gas-vapor mixture; $C_{\mathrm{H} 2 \mathrm{O}}-$ mass concentration of water vapors in the gas-vapor mixture; $C_{\mathrm{N} 2}-$ mass concentration of nitrogen in the gas-vapor mixture; $C_{\mathrm{O} 2}$ - mass concentration of oxidizer in the gas-vapor mixture; $D$ - diffusion coefficient, $\mathrm{m}^{2} / \mathrm{s} ; E_{\mathrm{r}}-$ activation energy of a chemical reaction, $\mathrm{J} / \mathrm{mol} ; g_{\mathrm{y}}$ - acceleration of gravity, $\mathrm{m} / \mathrm{s}^{2} ; H$-dimension of solution area in the projection on axis $x, \mathrm{~m} ; L$ - dimensions of solution area in the projection on axis $y, \mathrm{~m} ; k_{\mathrm{r}}$ - pre-exponential factor of the thermal decomposition reaction, $\mathrm{s}^{-1} ; Q$ - thermal effect of reaction, $\mathrm{J} / \mathrm{kg} ; Q_{\mathrm{d}}$ - thermal effect of coal thermal decomposition, $\mathrm{J} / \mathrm{kg} ; Q_{\mathrm{eC}}-$ thermal effect of combustible liquid evaporation, $\mathrm{J} / \mathrm{kg} ; r$ - coordinate of spherical system; $R_{\mathrm{d}}$ - radius of CWSP droplet, m; $R_{\mathrm{t}}-$ universal gas constant, $\mathrm{J} /(\mathrm{mol} \cdot \mathrm{K}) ; t$ - time, $\mathrm{s} ; T$ - temperature, $\mathrm{K} ; T_{\mathrm{C} 0}$ - initial temperature of CWSP particle, $\mathrm{K} ; T_{\mathrm{d}}-$ temperature of CWSP particle, $\mathrm{K} ; T_{\mathrm{d}}{ }^{\mathrm{max}}$ - maximum temperature of CWSP particle, $\mathrm{K} ; T_{\mathrm{g}}$ - temperature of injected high temperature gases, $\mathrm{K} ; T_{\mathrm{g} 0}$ - initial temperature of high-temperature gases, $\mathrm{K} ; T_{\mathrm{w} 0}$ - initial temperature of water, $\mathrm{K} ; u-$ component of velocities of fuel vapors in the projection on the axis $x, \mathrm{~m} / \mathrm{s} ; U_{\mathrm{g}}$ - velocity of injected high temperature gases, $\mathrm{m} / \mathrm{s} ; v$ - component of velocities of fuel vapors in the projection on the axis $y, \mathrm{~m} / \mathrm{s} ; W$ - chemical reaction mass velocity, $\mathrm{kg} /\left(\mathrm{m}^{3} \cdot \mathrm{s}\right) ; W_{\mathrm{d}}-$ mass rate of coal thermal decomposition, $\mathrm{kg} /\left(\mathrm{m}^{3} \cdot \mathrm{s}\right) ; W_{\mathrm{e}}-$ mass rate of evaporation, $\mathrm{kg} /\left(\mathrm{m}^{2} \cdot \mathrm{s}\right) ; W_{\mathrm{eC}}-\mathrm{mass}$ rate of evaporation of combustible liquid, $\mathrm{kg} /\left(\mathrm{m}^{2} \cdot \mathrm{s}\right) ; W_{\mathrm{ew}}-$ mass rate of water evaporation, $\mathrm{kg} /\left(\mathrm{m}^{2} \cdot \mathrm{s}\right) ; x, y-\mathrm{Cartesian}$ coordinates, $\mathrm{m} ; \beta$ - coefficient of thermal expansion, $\mathrm{K}^{-1} ; \beta_{\mathrm{r}}$ - chemical reaction temperature exhibitor; $\gamma$ - kinematic 
viscosity, $\mathrm{m}^{2} / \mathrm{s} ; \Delta t$ - time step, $\mathrm{s} ; \Delta x, \Delta y, \Delta r$ - steps on coordinate $x, y, r, \mathrm{~m} ; \eta$ - volume fraction of component of gas mixture; $\lambda$ - thermal conductivity, $\mathrm{W} /(\mathrm{m} \cdot \mathrm{K}) ; \xi$ - share of coal capable for thermal decomposition; $\rho$ - density, $\mathrm{kg} / \mathrm{m}^{3} ; \tau_{d}-$ ignition delay time, $\mathrm{s} ; \varphi$ - coordinate of spherical system; $\psi$ - current function, $1 / \mathrm{s} ; \omega$ - vorticity vector, $\mathrm{s}^{-1}$.

\section{Acknowledgements}

Research into the characteristics of CWSP ignition processes was funded by Russian Science Foundation (project 1519-00003). The optimization of the combustion of fuels based on coal and oil processing waste was performed within the framework of the strategic plan for the development of National Research Tomsk Polytechnic University as one of the world-leading universities.

\section{References}

[1] T. Takeshita, K. Yamaji, "Potential contribution of coal to the future global energy system," Environmental Economics and Policy Studies, vol. 8, pp. 55-87, 2014.

[2] A. E. Kontorovich, M. I. Epov, L. V. Eder, "Long-term and medium-term scenarios and factors in world energy perspectives for the 21 st century," Russ. Geol. Geophys., vol. 55, pp. 534-543, 2014.

[3] N. Lior, "Energy resources and use: The present situation and possible paths to the future," Energy, vol. 33, pp. 842$857,2008$.

[4] W. Wilczyńska-Michalik, R. Moryl, J. Sobczyk, M. Michalik, "Composition of coal combustion by products: The importance of combustion technology," Fuel Process. Technol., vol. 124, pp. 35-43, 2014.

[5] H. Wu, P. Glarborg, F. J. Frandsen, K. Dam-Johansen, P. A. Jensen, B. Sander, "Trace elements in combustion of solid recovered fuel and coal," Fuel Process. Technol., vol. 105, pp. 212-221, 2013.

[6] E. G. Gorlov, "Composite water-containing fuels from coals and petroleum products", Solid Fuel Chem., vol. 38, no. 6, pp. 40-50, 2004.

[7] D. O. Glushkov, S. V. Syrodoy, A. V. Zakharevich, P. A. Strizhak, "Ignition of promising coal-water slurry containing petrochemicals: Analysis of key aspects," Fuel Process. Technol., vol. 148, pp. 224-235, 2016.

[8] P. J. Stopford, "Recent applications of CFD modelling in the power generation and combustion industries," Appl. Math. Model., vol. 26, pp. 351-374, 2002.

[9] G. V. Kuznetsov, P. A. Kuibin, P. A. Strizhak, "Estimation of the Numerical Values of the Evaporation Constants of the Water Drops Moving in the High Temperature Gas Flow," High Temp., vol. 53, no. 2, pp. 254-258, 2015. 